\title{
2006s-05 \\ An Experimental Test of Taylor-Type Rules with Inexperienced Central Bankers
}

Jim Engle-Warnick, Nurlan Turdaliev

Série Scientifique
Scientific Series

Montréal
Mai 2006

(C) 2006 Jim Engle-Warnick, Nurlan Turdaliev. Tous droits réservés. All rights reserved. Reproduction partielle permise avec citation du document source, incluant la notice (C).

Short sections may be quoted without explicit permission, if full credit, including $\left({ }^{\circ}\right.$ notice, is given to the source.
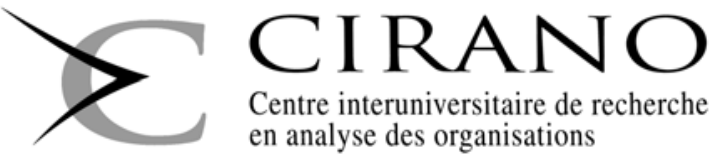

Centre interuniversitaire de recherche en analyse des organisations 


\section{CIRANO}

Le CIRANO est un organisme sans but lucratif constitué en vertu de la Loi des compagnies du Québec. Le financement de son infrastructure et de ses activités de recherche provient des cotisations de ses organisations-membres, d'une subvention d'infrastructure du Ministère du Développement économique et régional et de la Recherche, de même que des subventions et mandats obtenus par ses équipes de recherche.

CIRANO is a private non-profit organization incorporated under the Québec Companies Act. Its infrastructure and research activities are funded through fees paid by member organizations, an infrastructure grant from the Ministère du Développement économique et régional et de la Recherche, and grants and research mandates obtained by its research teams.

\section{Les partenaires / The Partners}

\section{Partenaire majeur}

Ministère du Développement économique,

de l'Innovation et de l'Exportation

\section{Entreprises partenaires}

Alcan inc.

Banque du Canada

Banque Laurentienne du Canada

Banque Nationale du Canada

Banque Royale du Canada

Bell Canada

BMO Groupe financier

Bombardier

Bourse de Montréal

Caisse de dépôt et placement du Québec

Fédération des caisses Desjardins du Québec

Gaz Métro

Hydro-Québec

Pratt \& Whitney Canada

Raymond Chabot Grant Thornton

\section{Autres partenaires gouvernementaux}

Industrie Canada

Ministère des Finances du Québec

Ville de Montréal

\section{Partenaires universitaires}

École Polytechnique de Montréal

HEC Montréal

McGill University

Université Concordia

Université de Montréal

Université de Sherbrooke

Université du Québec

Université du Québec à Montréal

Université Laval

Le CIRANO collabore avec de nombreux centres et chaires de recherche universitaires dont on peut consulter la liste sur son site web.

Les cahiers de la série scientifique (CS) visent à rendre accessibles des résultats de recherche effectuée au CIRANO afin de susciter échanges et commentaires. Ces cahiers sont écrits dans le style des publications scientifiques. Les idées et les opinions émises sont sous l'unique responsabilité des auteurs et ne représentent pas nécessairement les positions du CIRANO ou de ses partenaires.

This paper presents research carried out at CIRANO and aims at encouraging discussion and comment. The observations and viewpoints expressed are the sole responsibility of the authors. They do not necessarily represent positions of CIRANO or its partners. 


\title{
An Experimental Test of Taylor-Type Rules with Inexperienced Central Bankers
}

\author{
Jim Engle-Warnick ${ }^{\dagger}$, Nurlan Turdaliev ${ }^{*}$
}

\begin{abstract}
Résumé / Abstract
Nous avons mené une étude expérimentale dans le but de savoir si les règles de décision en matière de politique monétaire sont utilisées par les banquiers inexpérimentés au sein des banques centrales. Au cours de nos expériences, des sujets établissaient un taux d'intérêt à court terme dans un contexte d'économie informatisée dans le but de maîtriser l'inflation. Une grande majorité des sujets ont appris à maîtriser efficacement l'inflation. Nous sommes d'avis que les règles du type Taylor correspondent bien aux données liées aux choix et contribuent grandement à établir l'hétérogénéité du processus de décision. Notre étude est la première à recourir à l'organisation expérimentale des données sans, pour autant, perdre de vue les règles liées à la politique monétaire qui fait le plus l'objet de surveillance et d'analyse dans le domaine de l'économie.
\end{abstract}

Mots clés : économie expérimentale, jeux répétés, politique monétaire, règle Taylor

We experimentally test whether a class of monetary policy decision rules describes decision making in a population of inexperienced central bankers. In our experiments, subjects repeatedly set the short-term interest rate for a computer economy with inflation as their target. A large majority of subjects learn to successfully control inflation. We find that Taylor-type rules fit the choice data well, and are instrumental in characterizing heterogeneity in decision making. Our experiment is the first to begin to organize data experimentally with an eye on monetary policy rules for this, one of the most widely watched and analyzed decisions in economics.

Keywords: experimental economics, monetary policy, repeated games, Taylor rule

Codes JEL : C91, E42

\footnotetext{
* We thank John Galbraith, Adrian Pagan, Daniel Parent and participants at the 2004 Economics Science Association Conference in Amsterdam and the 2004 Canadian Experimental Economics Conference in Calgary for useful comments. We thank Sara Constantino and Julie Héroux for research assistance. We gratefully acknowledge the Economic and Social Research Council, UK and Nuffield College, University of Oxford, UK for financial support and the Centre for Interuniversity Research and Analysis on Organizations (CIRANO) and the Bell University Laboratory in Electronic Commerce and Experimental Economy for use of the experimental laboratory.

${ }^{\dagger}$ Department of Economics, 855 Sherbrooke St. W., McGill University, Montreal, Québec, H3A 2T7, Canada, email: jim.engle-warnick@mcgill.ca, tel.: (514) 398-1559; fax: (514) 398-4938.

$\$$ Department of Economics, 855 Sherbrooke St. W., McGill University, Montreal, Québec, H3A 2T7, Canada, email: nurlan.turdaliev@mcgill.ca, tel.: (514) 398-4827; fax: (514) 398-4938.
} 


\section{Introduction}

The importance of monetary policy decision rules, which are frameworks within which central banks are committed to make their decisions, has grown rapidly over the last decade. A purpose of adopting such rules is to provide central bankers with more effective and robust monetary policy (through better and more stable actions) and to help the public better understand central banks' actions (through better transparency of those actions). The growing importance of monetary policy rules is apparent when one considers the amount of research conducted in this area (e.g., Taylor 1999a and Bernanke and Woodford 2005), and the influence of this research on policy makers.

There has been an active debate about whether monetary policy is better conducted by pursuing targeting rules or instrument rules (e.g., Svensson 2003 and McCallum and Nelson 2005). Inflation targeting is an example of a targeting rule, which involves a public commitment by the central bank to a policy for an inflation rate. Recently several central banks have adopted inflation targeting, and indeed the recent nominee for chairmanship of the Federal Reserve in the United States, Ben Bernanke, is an advocate of such a monetary policy rule.

The Taylor rule (Taylor 1993), which linearly maps the inflation gap (the difference between inflation and a given inflation target) and output gap (the difference between output and potential output) into the central bank's instrument (say, the short-term nominal interest rate), is an example of a simple instrument rule. ${ }^{1}$ Substantial research has been done in investigating whether the Taylor rule is an accurate description of central bank's behavior (see Clarida, Gali and Gertler 1998), and the Taylor rule has inspired very active theoretical research of the properties of simple policy rules such as optimality and robustness (see Svensson 1997, Levin, Wieland, and Williams 1999).

From a historical perspective, the Taylor rule provides a useful framework to examine

\footnotetext{
${ }^{1}$ Such a decision rule specifies the central bank's instrument as a function of central bank's information.
} 
monetary policy over time. Using this approach, Taylor (1999b) assesses several periods in history of U.S. monetary policy, identifies turning points in monetary policy, and quantifies the size of past mistakes as well as the degree of effectiveness of different policy rules. John Taylor provides the following summary for this research (see Taylor 1999a): simple policy rules behave nearly optimally and are more robust than complex rules.

In this paper, we present a new use for Taylor-type rules: as a tool for describing how inexperienced economic agents attempt to achieve a target level of inflation in a computer economy. In our economics experiments, inexperienced 'central bankers' are asked to conduct monetary policy in a laboratory to maximize 'social welfare', which is directly related to their payoff. The model economy is such that a Taylor-type rule is optimal (more specifically, in this model inflation targeting leads behaviorally to a Taylor-type rule). Our question is whether Taylor-type rules describe decision making of subjects in this environment. If so, then we take a step forward understanding how people come to understand a central bank decision-making problem, we strengthen the argument that the Taylor rule is useful in communicating central bank policy, and we begin to organize choice data collected in controlled experiments on monetary policy.

For concreteness, let us briefly discuss the policy rules we study. The simplest Taylor-type rule is

$$
i_{t}=\gamma_{0}+\gamma_{1}\left(\pi_{t}-\bar{\pi}\right)+\gamma_{2} x_{t}
$$

where $i_{t}$ is the central bank's instrument chosen at time $t, \pi_{t}$ is the inflation rate, $\bar{\pi}$ is a given inflation target, $x_{t}$ is the output gap (the difference between log-output and log-potential output). The coefficients $\gamma_{1}$ and $\gamma_{2}$, i.e., the weights placed on inflation and output, are positive. Taylor suggested $i_{t}=4+1.5\left(\pi_{t}-2\right)+0.5 x_{t}$ in his original paper. The optimal monetary policy in our models has either this form or has in addition a lagged inflation gap term:

$$
i_{t}=\gamma_{0}+\gamma_{1}\left(\pi_{t}-\bar{\pi}\right)+\hat{\gamma}_{1}\left(\pi_{t-1}-\bar{\pi}\right)+\gamma_{2} x_{t} .
$$


In our experiments, subjects repeatedly set the discount rate in two simple economies in which Taylor-type rules are optimal. The experiments provide a tough test of the theory: the subjects did not know they were controlling an economy, nor did they know the specific equations governing the dynamics of the system. Nevertheless, we find that Taylor-type rules, with an additional term for smoothing, explain a significant share of the variance of the data, particularly when we fit them on a subject-by-subject basis. In other words, we find in our laboratory study that linear rules are useful for describing behavioral outcomes in a central bank problem with inflation targeting.

Perhaps most importantly, as mentioned in Taylor (1999c), it is important to have the inflation response coefficient $\gamma_{1}$ larger than 1 ('stability threshold'). ${ }^{2}$ Most of the subjects in our experiments successfully learn to get this right: the estimated $\gamma_{1}$ is just above 1 . By contrast, the estimate for the unsuccessful subjects is less than 1 . We go on to show that the primary incentive in the model is to achieve exactly that: despite the fact that the optimal solution calls for a higher weight on inflation, there is little increase in expected payoff for doing so. Our study is the first to identify Taylor-type rules as good descriptions of the behavioral outcome when subjects try to achieve an inflation target.

In practice, monetary policy rules may be difficult to infer from central bank decision making for a variety of reasons. For example, Judd and Rudebusch (1988) note that the inflation target is not observable to the econometrician, causing it to be lumped in a regression constant when estimating the coefficients of the rule. Also, central bankers react to different data than are available to the econometrician: the data sets commonly used to identify decision rules contain revisions that were not available to the central bank at the time they set their instrument (Orphanides, 2001). Finally, there are multiple ways to measure potential output in an economy. None of these difficulties are present in laboratory data, providing the cleanest test we can think of for the decision rule.

\footnotetext{
${ }^{2}$ Taylor attributes a better monetary policy in the 1980s and 90 s to $\gamma_{1}$ being above 1 as opposed to the 1960s when it was below 1.
} 
There have been at least two other related studies of central bank decision making in the laboratory. Arifovic and Sargent (1999) find that policy makers can find ways to achieve a time-inconsistent optimal inflation rate in an expectational Phillips curve model. In their experiment policy makers set the inflation target and consumers report inflation expectations. Blinder and Morgan (2004) study the advantages of committee decision making in a problem more similar to ours: their question is whether groups or individuals identify and respond to a shock to money demand better. Our study may shed additional light on these existing results by specifically studying the decision rules that subjects use while determining monetary policy.

\section{Experimental Design and Procedures}

\subsection{The macroeconomic model}

We first consider a dynamic general equilibrium model with money and nominal price rigidity. Like in the Keynesian IS-LM approach, monetary policy affects the real economy in the short run. However, like in the new classical approach, equations for aggregate variables are derived from the optimization problems of households and firms. As a result, economic behavior in the current period depends on expectations of the future monetary policy.

The model has two aggregate equations:

$$
\begin{aligned}
& x_{t}=E_{t} x_{t+1}-b\left(i_{t}-E_{t} \pi_{t+1}\right)+u_{t}, \\
& \pi_{t}=a_{1} E_{t} \pi_{t+1}+a_{2} x_{t}+v_{t} .
\end{aligned}
$$

The first equation indicates a negative relationship between the output gap $x_{t}$ and the expected real interest rate $i_{t}-E_{t} \pi_{t+1}$ (it is sometimes referred to as an "IS" curve). It is obtained by log-linearizing the household Euler equation. The second equation is a Phillips curve that shows a positive relationship between inflation and the output gap. It can be 
derived from an environment of monopolistically competitive firms. The equation is obtained by log-linearizing around the steady state of the aggregate firms' pricing decision.

Now we slightly generalize this model to allow for persistence:

$$
\begin{aligned}
& x_{t}=q\left(x_{t-1}\right)+(1-q) E_{t} x_{t+1}-b\left(i_{t}-E_{t} \pi_{t+1}\right)+u_{t}, \\
& \pi_{t}=r \pi_{t-1}+(1-r) a_{1} E_{t} \pi_{t+1}+a_{2} x_{t}+v_{t} .
\end{aligned}
$$

We added a lagged output gap to the first equation and a lagged inflation to the second one. We justify this adjustment on the basis of empirical observation (see Fuhrer, 1996), and on the basis of theoretical work on adjustment costs. The addition of lagged inflation to the second equation can be justified by introducing adaptive expectations into the model. In the particular case of $q=1$ and $r=1$ we obtain the backward-looking model studied in Svensson (1997). This type of model does not take into account agents' responses to changes in policies, and thus assumes that the model parameters do not change as policy changes. ${ }^{3}$ The advantage is the great simplification of the analysis obtained by treating the private sector's expectations as an adaptive process. After some arrangements we can obtain the following model: ${ }^{4}$

$$
\begin{aligned}
x_{t+1} & =\beta_{1} x_{t}-\beta_{2}\left(i_{t}-\pi_{t}\right)+\nu_{t+1} \\
\pi_{t+1}-\bar{\pi} & =\alpha_{1}\left(\pi_{t}-\bar{\pi}\right)+\hat{\alpha}_{1}\left(\pi_{t-1}-\bar{\pi}\right)+\alpha_{2} x_{t}+\epsilon_{t+1} .
\end{aligned}
$$

In general, the coefficients $\alpha_{2}$ and $\beta_{2}$ are assumed to be positive, and all others are nonnegative; in addition, $\beta_{1}<1$. In this economy, inflation is serially correlated and increasing in lagged output. Output is serially correlated and decreasing in the lagged short-term real

\footnotetext{
${ }^{3}$ We can usefully think of our model as analogous to a long line of models in experiments in Industrial Organization, in which human subjects set prices in a game against computer robot buyers. In these experiments, the goal is to learn as much as possible about seller behavior by isolating it apart from the buyers. In our experiment, we wish to learn as much as possible about the policy maker, and we plan to add human consumers in future work.

${ }^{4}$ For more details about this kind of models, see Clarida, Gali Gertler (1999), Fuhrer and Moore (1995a, 1995b), Ball (1997).
} 
interest rate $i_{t}-\pi_{t}$. In this dynamic economy $\bar{\pi}$ is the long-run inflation rate and the long-run output gap is zero (when optimal monetary policy is pursued). ${ }^{5}$

The monetary authority's objective is to choose a sequence of federal funds rates $\left\{i_{\tau}\right\}_{\tau=t}^{\infty}$ to minimize:

$$
E_{t} \sum_{\tau=t}^{\infty} \delta^{\tau-1} \frac{1}{2}\left(\pi_{\tau}-\bar{\pi}\right)^{2}
$$

where $\bar{\pi}$ is the inflation target.

The central bank's policy rule can be written as

$$
i_{t}=\gamma_{0}+A(L) \pi_{t}+B(L) x_{t}
$$

where $A(L)$ and $B(L)$ are lag polynomials (note that we surpress $\bar{\pi}$ hereafter). The lower the degree of the polynomials $A$ and $B$ the 'simpler' is the policy rule. As was mentioned before, the optimal policy rules in our models have the following form:

$$
i_{t}=\gamma_{0}+\gamma_{1} \pi_{t}+\hat{\gamma}_{1} \pi_{t-1}+\gamma_{2} x_{t}
$$

where $\hat{\gamma}_{1}=0$ if $\hat{\alpha}_{1}=0$.

\subsection{The Experimental Design}

We ran two versions of the model. In Model 1 only the first lag of inflation affects current inflation ( $\hat{\alpha}_{1}$ is zero), and in Model 2 we distribute the effect of inflation over an additional lag. For Model 1 we used Weymark's (2004) coefficient estimates of the Canadian economy, rounding down $\beta_{1}$ to ease the demands of tricky dynamics on our subjects. We chose these coefficients because we wanted the system dynamics to be somewhat consistent with a real

\footnotetext{
${ }^{5}$ Our model generalizes Svensson's model, in which inflation is assumed to have a unit root. In Svensson's model inflation and output are increasing in an exogenous variable, which provides a potentially interesting addition for further study.
} 
economy, and we wanted to leave the door open for future study of open economy issues. The coefficients are presented in Table 1 . We set both the potential level of output and the long-run inflation rate at 5.00, we set the inflation target at 5.00 and we always started the system in the steady state.

It can be shown that the optimal solution for Model 1 is a Taylor-type rule, and for Model 2 a linear rule that adds non-zero weight to the first lag of inflation. The optimal rule for Model 1 is:

$$
i_{t}=5.00+3.22 \pi_{t}+1.87 x_{t},
$$

and the optimal rule for Model 2 is:

$$
i_{t}=5.00+5.00 \pi_{t}+0.533 \pi_{t-1}+1.60 x_{t} .
$$

While we did not expect subjects to apply optimal weights to the relevant variables, our design does make the following testable predictions: (1) from Model 1 to Model 2, the relative weight on inflation should increase, and (2) in Model 2 but not in Model 1, non-zero weight should be placed on the first lag of inflation.

For inexperienced subjects, this is a very difficult decision-making problem. Imagine you are balancing a broom with the handle in the palm of your hand and the broom head up in the air. The location of the head of the broom is analogous to inflation and the location of your hand the instrument; your target is a vertical broom. Now imagine the head of the broom starts to move away from you (i.e., inflation increases past the target). You must move your hand past the physical location of the broom head to bring it back towards you (i.e., you must set the instrument higher than the rate of inflation), and as the broom moves towards you, you must bring your hand back with it (i.e., you must reduce the instrument as inflation nears the target). It is not obvious that the feedback subjects receive while playing the game will be as useful as the visual feedback one receives balancing the broom. 


\subsection{Experimental Procedures}

Our design presents a tough test for Taylor-type rules, because it does not allow subjects to bring prior information about monetary policy to bear on their decision making: subjects were not told the decisions they were making had anything to do with the economy, and they were not shown the equations driving the system. ${ }^{6}$ Instead they were presented with "chip levels in two containers labelled Container A and Container B", told that the levels were related to each other and the instrument, that increasing the instrument would tend to lower the chip levels, and that each period the relationships were computed and randomness was added to each chip level. Container A actually corresponded to output and Container B to inflation. The goal was to keep the chip level in Container B (i.e, inflation) as close to 5.00 as possible. Subjects were told that the relationships would not change during the entire session, and that the randomness was independent and identical in each period.

Upon arriving at the experimental laboratory, subjects were seated in front of a computer screen. Their decision-making consisted of entering a number for the instrument with up to two decimal places, and clicking an ok button. The screen revealed the entire history of the game, including all past realizations of inflation, output, and all past instrument values. The experiment was programmed and conducted with the software z-Tree (Fischbacher 1999).

Subjects were able to practice the game for no pay before playing it once for pay (as in the schooling choice problem in Houser, Keane, and McCabe, 2004). The practice sessions were set up so that there were five 10-period games, followed by two 25-period games, followed by 50-period games. Subjects were told that they could practice as often as they liked, with the limitation that the lab was booked for an hour and a half. If subjects wished to play the game for pay after practicing only 10-period games, we suggested they try at least a 25-period game first to improve their chance of earning money; performance in 10-period games is not a good predictor for 50-period games because it may take longer than 10 periods

\footnotetext{
6 The informational conditions were similar to those in Blinder and Morgan (2004).
} 
to lose control of the system. When they did play the game for pay, subjects were told that all the rules and relationships remained the same, except that the game for pay would last either 51 or 52 periods, and that they would not be told which. ${ }^{7}$ To the subjects in every session, either outcome was equally probable; this breaks up an end-game strategy, and we only analyze data up to fifty periods. All subjects in both treatments experienced exactly the same shocks in the game for pay, which were drawn from the normal distribution with mean zero and standard deviation 0.15 using the random number generator in Ox (Doornik, 2002).

We paid subjects using a scheme similar to that used in Arifovic and Sargent (1999). This procedure communicates earnings when the earnings depend on a loss function. ${ }^{8}$ Each period, a subject's loss was converted to "period points" (say, $P_{t}$ ) by adding 0.10 to the computed loss. For subjects who were doing reasonably well, this transformed the period's result into a positive number. The subjects earnings (say, E) were $\$ 25.00$ times the ratio of the sum of all their period points to the sum of the maximum possible period points they could have earned:

$$
E=25.00 \sum_{t=1}^{50} P_{t} / 5.0 .
$$

It can be shown that this payoff scheme provides the same incentive as minimizing losses. Thus the maximum theoretical earnings for decisions were $\$ 25.00$, if no losses ever occurred. We have discovered through practice that it is possible to earn $\$ 23.00$. Although earnings may be displayed as negative, subjects never earned less than the show-up fee. The display presented the period loss, period points, and the earnings that would be made if the current period were the last period of play.

We ran the experiments at the Bell University Laboratory in Electronic Commerce and

\footnotetext{
${ }^{7}$ For programming purposes we flipped a coin before the first session and used that result to run 52-period games.

8 The quadratic loss function seems difficult to understand for at least two reasons: (1) it is relatively flat whenever inflation is close to the target and (2) during the entire session, the loss function constantly provides only negative feedback regarding subjects' performance.
} 
Experimental Economy in Montreal in the winter term of 2004. The subjects earned a $\$ 10.00$ show-up fee (which covers the cost of public transportation to travel to the lab, which is not located on campus, for many of our subjects). Sixty-eight subjects participated with Model 1 earning an average of $\$ 26.68$, and seventy subjects participated with Model 2 earning an average of $\$ 26.60$, including the show-up fee. Subjects varied by the amount of practice games they played, and were paid and dismissed as they finished. Each subject played at her/his own pace. Sessions did not last beyond an hour and a half. We analyze only the games for pay.

\subsection{Discussion of the Experimental Design}

Our experiment presented the subjects with a rather difficult decision-making problem. In fact it surprised us when we ran our initial sessions that few learned how to control inflation, thus we had to learn how to conduct our experiments in such a way that we could collect meaningful data. Based on our experience with two pilot sessions we modified the design in the following ways. The data, which simply told us whether a reasonable proportion of subjects were able to make non-negative earnings, are available upon request.

First, we switched from modelling inflation with a unit root to the Canadian economy coefficient estimates; with the unit root subjects could not control the system. Second, we decreased the standard deviation of the shocks from 0.25 to 0.15 . Third, we simplified our instructions and added a brief reference section for easy look-up during the session. And fourth, we made learning quicker by building up the number of rounds slowly in the practice part of the session from ten to twenty-five to fifty.

At first we were concerned that we had oversimplified the design, but the results suggest otherwise. In Model 1 only fifty-six out of sixty-eight subjects successfully controlled the system, and fifty-eight out of seventy did so in Model 2. 


\section{Results}

Figure 1 shows the time series of inflation, output gap, and instrument choice if the central bank uses the optimal rule in Model 1 in our experiments. This simulation is valid for every subject because every participant experienced the same sequence of shocks in the games for pay. The figure shows that it is possible to limit inflation (the solid line) between $4.5 \%$ and $5.5 \%$ by selecting instrument values roughly in the range from 4 to 6 .

[insert Figures 1 and 2 here]

Figure 2 show the same series for Model 2. The more complicated dynamics require a slightly wider range of instrument selection, but again one can see that inflation can be kept within a very narrow band of control. Due to the way we distributed the lagged effect of inflation and due to the identical sequence of shocks, one can also glean from the two figures that when optimally controlled, the time path of inflation is similar in both models.

Despite the fairly low variance in the shocks (0.15) there is still plenty of scope for monetary policy. Figures 1 and 2 show that to optimally control the system the instrument must vary between roughly 3.75 and 6.25 for Model 1, and between 3.0 and 6.5 for Model 2. Thus the decision-making problem requires the subjects to use an active strategy for controlling the economy, i.e., the problem is not a trivial one.

Sixty-eight subjects played the game with Model 1 driving the system, and of these fiftysix made nonnegative earnings (negative earnings were converted to zero earnings). The mean sum of period losses (std. dev.) for the successful subjects was 1.15 (0.98), and for the unsuccessful ones was 551.18 (1821.87). If one were to use the optimal rule total losses would be 0.57 ; thus the successful subjects performed very well.

Seventy subjects played the game with Model 2 driving the system, and of these fifty-eight made nonnegative earnings. The mean sum of period losses (std. dev.) for the successful 
subjects was 1.03 (0.89), and for the unsuccessful ones was 579.49 (1783.72). If one were to use the optimal rule total losses would be 0.57 ; thus, again, the successful subjects performed very well.

\subsection{Individual Results}

We found it rather fun to look at the time path of decision making of some our potential future central bankers. Figures 3 - 6 present selected results from four individual subjects. Figure 3 presents a very successful subject who kept inflation almost within the narrow band of optimal control; perhaps a committee nomination is in his or her future. Figure 4 shows the decisions of a subject who began to lose control in the middle of the game but seemed to be regaining it. Around period 24 this subject continued to decrease the level of the instrument even while inflation began to increase. At period 27 the the subject moved the instrument above the inflation level and eventually brought it back down. The smaller inflation peak at period 42 shows the subject regaining control in a skilled manner. Maybe we should consider bringing this person in someday to troubleshoot a stormy economy. ${ }^{9}$

\section{[insert Figures 3-6 here]}

Figures 5 and 6 illustrate what can happen when control is lost. Figure 5 shows the decisions of a subject who makes very small changes in the instrument for 15-20 periods, then as inflation begins to decrease, decreases the instrument for too long, following with sharp increase in the instrument, then a sharp decrease, and finally another sharp increase. By contrast with Figure 4, this subject experienced wider swings over time and the future does not look promising. Figure 6 shows the decisions of another subject who made very small changes for more than 25 periods and apparently did not know what to do with the instrument as inflation constantly decreased.

\footnotetext{
${ }^{9}$ Unfortunately, anonymity requirements make it impossible to identify these two promising individuals.
} 
Figures 7 - 10 present selected results from four individual subjects experiencing Model 2. Figure 7 shows another example of very tight control, and Figure 8 shows a recovery. Figure 9 presents an interesting simple threshold decision rule: when inflation dropped below a threshold, the subject sharply lowered the instrument to bring inflation back up toward the target. S/he returned the instrument to the initial value and held it there, apparently waiting for another threshold to be exceeded. Figure 10 is an example of loss of control due to waiting too long to move the instrument and then not moving it enough.

\section{[insert Figures 7 - 10 here]}

\subsection{Aggregate Results}

Our data contain fifty decisions for over fifty subjects in each treatment, thus we begin our analysis with panel data estimation. We must take care doing this for two reasons. First, our prior was that the decision to set the instrument in period $t$ would be affected by the decision that was taken in period $t-1$, either because of inertia or a taste for smoothing on the part of the subjects. In this case one must instrument for the lagged dependent variable on the right hand side of the equation. Second, if coefficients are heterogeneous with respect to individual subjects, imposing the restriction of homogeneity can result in severely biased estimates. We address these issues one at a time in the following analysis.

We ran a fixed effects panel regression for both models on the data from the successful subjects. ${ }^{10}$ Table 2 presents the results, located in the column labelled "Fixed Effects". We estimated an equation with the instrument as the dependent variable and the following

\footnotetext{
10 Eliminating the unsuccessful subjects from the analysis primarily biases the coefficient estimate on inflation upward with respect to the randomly drawn subject population. We must remove these subjects because once they lose control of the process they are constrained: the optimal strategy is not available to them any more because we limited the range of the instrument, thus our analysis is conditional on successful control. We believe this is not a problem because in real life we typically observe decisions made by people who have an understanding of the process. We also note that there was an obvious breakpoint between successful and unsuccessful performance.
} 
independent variables: lagged instrument, inflation, lagged inflation, output, and lagged output. We present results from this general model; none of the conclusions we make are affected by reasonable changes to the the set of independent variables.

These regressions provide some evidence that the lagged instrument affects decision making, with positive and significant coefficients on the lagged instrument. The estimate of the critical coefficient, i.e., the coefficient on inflation, is 1.10 for Model 1 and 1.00 for Model 2, and significantly different from zero for both; this coefficient should be greater than 1 to achieve control of the system. The coefficient on output is positive and significant in both models. And the coefficients on lagged inflation and output are negative and significant in most cases. The r-squared statistics for these models is in the $0.40-0.50$ range, indicating that there is quite a bit of variance of decision making left to explain.

Since the lagged dependent variable might be a part of the effective strategy that subjects employ, we re-estimated the same model instrumenting for this variable using the one-stage Arellano and Bond (1991) procedure. This procedure uses all available lags of the lagged dependent variable as instruments for it. The results are presented in the second column of Table 2 labelled "Arellano and Bond".

All coefficients for both models, except lagged output in Model 2, are significant in these regressions. Once again, the lagged dependent variable appears to affect decision making in both models, though with a larger coefficient in Model 2 than in Model 1. Estimates for the coefficient on inflation are a bit greater than 1 for both models, and positive weight is placed on output for both models. What is striking is that the weights on the important variables, i.e., inflation and output, appear nearly identical in both cases. Recall also that Model 2 calls for positive weight on lagged inflation but the subjects appear to be placing negative weight on it instead.

Our earlier discussion suggested the existence of heterogeneity among our subjects, so we present results relaxing the restriction of homogeneity of the coefficients of the decision rule. 
Pesaran and Smith (1995) suggest estimating the coefficients individually and aggregating the estimates in this case, thus we ran OLS regressions on a subject-by-subject basis estimating the same model we reported in Table 2. We report the results in Figures $11-15$.

Figure 11 shows the distribution of r-squared statistics for both models. Notice that the horizontal axis labels the higher of the numbers defining each bin. For example, in Figure 11, Model 1, there were 25 r-squareds that fell between 0.90 and 1.0. Both distributions are concentrated in the range above 0.60 , the mean of both distributions is approximately 0.80 , indicating a much better fit than we found with the panel regressions. Figure 12 presents the distribution of estimated coefficients for the lagged instrument, and here we find similar results for both models with a modal estimate around 0.16 , and means of 0.14 and 0.17 for Models 1 and 2, which is smaller than the panel data estimates but still positive. By far most of the estimates lie between 0 and 1.

Figure 13 shows how individual subjects reacted to inflation. A clear majority of subjects in both treatments acted as though they placed a weight greater than 1 on inflation. The mean coefficient estimates are 1.07 and 1.10 for the two treatments. Figure 14 shows the distribution of estimated weights on the lagged inflation coefficient; the means here are close to zero and once again the distributions are similar. Figures 15 and 16 present estimated coefficients for output and lagged output; once again, the distributions are similar, with positive mean weight placed on output and roughly zero mean weight placed on its first lag. The means of the estimated coefficients on output are 0.17 and 0.21 for Model 1 and Model 2 , which is lower than the optimal rule coefficients.

Four things struck us with the results of the individual regressions. First, the fit of the OLS regressions was high, with averaged r-square statistics of 0.80 . Second, the means of OLS estimates of the coefficients told the same general story as the estimates in the panel regressions. Third, the distributions of the estimates of the coefficients were similar across the two treatments; so similar, in fact, that we thought we had put together the histograms 
incorrectly at first. And fourth, these distributions of the OLS estimates look very different from what a sampling distribution of OLS estimates would look like in a sequence of repeated experiments with the same structure (i.e., asymptotically normal and resemblance to normal in a small sample). This last point bolsters the notion that the subjects are not all the same.

\subsection{Discussion of the Results}

We simulated our two models of the economy to understand the incentives faced by our inexperienced central bankers. For the first of these simulations we assumed the central bankers target inflation, i.e., they keep their eye only on container B while setting their instrument, placing zero weight on all other variables. We thought this a good starting point because it is reasonable for a subject with no experience to fixate on the container that determines her payoff, and because many subjects told us in post-experiment protocols (which were announced after the experiment and were voluntary) that they focused on Container B.

We varied the weight on inflation from 0.50 to 5.0 in increments of 0.10 , averaging the sum of the period losses incurred by the central banker over 10,000 simulations of the economy. The result for Model 1 is presented in the top panel of Figure 17. The horizontal axis is the weight on inflation in the decision rule (with all other weights zero), and the vertical axis presents the expected payoff in Canadian dollars. The figure reveals that the payoff function is steep for weights on inflation less than 1.0, and then it flattens out for weights up to 3.0. The top panel of Figure 18 shows a similar situation for Model 2. Thus there is a strong incentive to get the weight just above 1.0.

Next we took the decision rule coefficients from the data, using the mean estimate for all variables except inflation, which we varied from 0 to 4.5. The results for Model 1 and Model 2 are presented in the middle panels of Figures 17 and 18. Once again the payoff function is steep roughly until the weight on inflation surpasses 1.0 and then flattens out. 
The figures show the locations of the means of the estimated OLS coefficients from the data, which were 1.07 for Model 1 and 1.10 for Model 2. Both means are located near where the payoff function levels off, at the top of the steep part for weights less than one.

Then we repeated the exercise varying the coefficient on output from 0 to 2.9 while holding all the weights on all other variables constant at the mean of the OLS coefficients. These results are in the lower panels of Figures 17 and 18. These panels reveal that the payoff function is flat with respect to changes in the weight given to output. All expected payoffs in this range are above $\$ 20$.

How much better could the subjects have done with the optimal rule? In Model 1, the expected payoff for the mean of the estimated rules is $\$ 20.93$ vs. $\$ 21.50$ for the optimal rule. In Model 2, the expected payoff for the mean of the estimated rules is $\$ 21.38$ vs. $\$ 21.9$ for the optimal rule. Clearly not much is being lost for playing what we conjecture to be a heuristic, with attention primarily focused on inflation, with a bit of short-term interest weight smoothing, and with sub-optimal weight on output.

Our conjecture is that subjects used a simple heuristic, which performed nearly as well as the optimal rule, to solve this problem. To investigate the possibility that the successful subjects climbed just to the top of the hill while the unsuccessful ones did not make it off the steep part of the hill, we ran a regression on the first 25 decisions of the unsuccessful subjects in both economies. ${ }^{11}$ We found a mean weight of 0.30 on inflation in Model 1 , and a result statistically insignificant from 0 for Model 2. While we cannot say for certain, and neither can our subjects, it appears plausible that learning in this environment involves climbing the part of the payoff function where the weight of inflation is less than one.

While there is general agreement among macroeconomists that the weight placed on inflation must be greater than 1.0, there is less agreement as to how high above 1.0 the weight should be. Our results thus illustrate that in our models a wide range of decision-rule

\footnotetext{
11 We limited this analysis to the first 25 decisions to avoid problems with constrained decisions that occurred after a loss of control.
} 
parameters do nearly as well as the optimal rule, as long as the weight is just above 1.0. The incentive is to get the weight on inflation over 1.0, but beyond that there is not enough incentive to perfect the rule. ${ }^{12}$ Our results also illustrate the finding that Taylor-type rules are instrumental in characterizing heterogeneity in decision making of inexperienced central bankers in our two computer economies.

\section{Conclusion}

We infer Taylor-type linear decision rules from the observed choices of inexperienced central bankers in the experimental laboratory where we know the details of the macro economy. Since we know the details of the economy, we bypass the typical problems in practice inferring monetary decision rules, such as unobservable inflation targets, ex-post revised macro data, and difficulties measuring an economy's potential output. In our experiments subjects set the short-term interest rate with inflation as their target. The results suggest that a linear decision rule fits a large portion of the variance of decisions of subjects who learned how to control inflation, particularly when we fit decision rules to each subject individually, and when we include a term for smoothing. We find little difference in behavior between experimental treatments despite apparent success in controlling the computer economies.

Our results showed that our successful bankers, on average, achieved an apparent weight of something very close to 1 on inflation, while our unsuccessful bankers achieved a weight of less than 1. We illustrated the fact that the primary behavioral incentive for bankers in this problem is to get the weight of inflation just above 1 , and that there is little incentive to achieve a weight higher than that. We found that Taylor type rules, when they control for behavioral tendencies such as smoothing, are an excellent tool to get at the heterogeneity in this decision-making problem.

\footnotetext{
${ }^{12}$ Houser, Keane, and McCabe (2002) made a similar finding in a dynamic decision problem mimicking the choice of schooling.
} 
We do not suggest that our experiments provide evidence that central banks use Taylortype rules, but we believe that we have taken a step in the direction of learning how inexperienced economic agents react in environments that model important issues in macroeconomics, and learning what rules are behaviorally relevant in such environments. To the extent that communication and transparency are important for central banks, our results suggest that linear rules can be a valuable means of communication, since they explain behavior by people in the extreme case where they know little about the process. We found that inflation targeting induced behavior that was explained well by linear decision rules. And as in the long line of experiments in IO, where inexperienced firms set prices, we begin to organize the data in the simplest of environments that we use to understand important policies.

Our study provides a foundation for exploration of a variety of issues in monetary economics. An obvious next step is to determine the parameter or set of parameters that induce different decision rules for different economies. We plan to add the exogenous variable to study behavior when exchange rates, interest rates, or output in other countries affect the economy. Indeed we can study the effect of central bank decision making in one country on another, with the ability to insert an optimal decision maker as a control in one of the economies. While we ran our first study using a simple backward-looking model, it will be important to test models in which economic agents react to the central bank's decision rule. Our experiment establishes a baseline result, suggesting that Taylor-type rules are useful for describing the behavior of inexperienced central bankers. 


\section{References}

Anderson, T. W. and Cheng Hsiao (1980), "Formulation and Estimation of Dynamic Models Using Panel Data," Journal of Econometrics, 18:1, 47-82.

Arellano, M. and S. Bond (1991) "Some Tests of Specification for Panel Data: Monte Carlo Evidence and an Application to Employment Equations," Review of Economic Studies, 58: $277-297$.

Arifovic, J. and T. Sargent (1999), "Laboratory Experiments with an Expectational Phillips Curve", available at http://www.sfu.ca/ arifovic/jresearch.html.

Ball, L. (1997), "Efficient Rules for Monetary Policy" NBER Working Paper No. 5952.

Bernanke, B. and M. Woodford, eds. (2005), The Inflation Targeting Debate, Chicago: University of Chicago Press.

Blinder, A. and J. Morgan (2004), "Are Two Heads Better than One? An Experimental Analysis of Group versus Individual Decision Making", forthcoming in Journal of Money, Credit and Banking.

Clarida, R., J. Gali, and M. Gertler (1998), "Monetary Policy Rules in Practice: Some International Evidence", European Economic Review, 42: 1033-1067.

Clarida, R., J. Gali, and M. Gertler (1999), "The Science of Monetary Policy: A New Keynesian Perspective", Journal of Economic Literature, 37(4), 1661-1707.

Doornik, J.A. (2002), "Object-Oriented Matrix Programming Using Ox, 3rd ed.”, London: Timberlake Consultants Press and Oxford: www.nuff.ox.ac.uk/Users/Doornik.

Estrella, A., and F. Mishkin (1999), "Rethinking the Role of NAIRU in Monetary Policy: Implications of Model Formulation and Uncertainty", In Monetary Policy Rules, J. Taylor, ed., Chicago: Chicago University Press.

Fischbacher, U. (1999), "z-Tree - Zurich Toolbox for Readymade Economic Experiments Experimenter's Manual", Working Paper Nr. 21, Institute for Empirical Research in Economics, University of Zurich.

Fuhrer, J., and G. Moore (1995a), "Inflation Persistence", Quarterly Journal of Economics, 440, 127-159.

Fuhrer, J., and G. Moore (1995b), "Monetary Policy Trade-offs and the Correlation between Nominal Interest Rates and Real Output", American Economic Review, 85(1), 219-239.

Houser, D., M. Keane and K. McCabe (2002), "Behavior in a Dynamic Decision Problem: An Analysis of Experimental Evidence Using a Bayesian Type Classification Algorithm", forthcoming in Econometrica. 
Judd, J.P. and G.D. Rudebusch (1998), "Taylor's Rule and the Fed: 1970-1997," Federal Reserve Bank of San Francisco Economic Review 3, 3-16.

Levin, A., V. Wieland, and J. Williams (1999), "Robustness of Simple Monetary Policy Rules Under Model Uncertainty", In Monetary Policy Rules, J. Taylor, ed., Chicago: Chicago University Press.

McCallum, B. and E. Nelson (2005), "Targeting versus Instrument Rules for Monetary Policy", Federal Reserve Bank of St. Louis Review",87:597-611.

Orphanides, A. (2001), "Monetary Policy Rules Based on Real-Time Data," American Economic Review 91, 964-985.

Pesaran, M. and R. Smith (1995), "Estimating Long-Run Relationships from Dynamic Heterogeneous Panels," Journal of Econometrics, 68:79-113.

Svensson, L. (1997), "Inflation Forecast Targeting: Implementing and Monitoring Inflation Targets", European Economic Review, 41:1111-1146.

Svensson, L. (2003), "What is Wrong with Taylor Rules? Using Judgement in Monetary Policy through Targeting Rules, Journal of Economic Literature, 41:426-477.

Svensson, L. (1997), “Optimal Inflation Targets, 'Conservative' Central Banks, and Linear Inflation Contracts", American Economic Review, 87: 98-114.

Taylor, J. (1993), "Discretion vs. Policy Rules in Practise", Carnegie-Rochester Conference Series on Public Policy 39: 195-214.

Taylor, J., ed. (1999a), Monetary Policy Rules, Chicago: Chicago University Press.

Taylor, J. (1999b), "A Historical Analysis of Monetary Policy Rules", In In Monetary Policy Rules, J. Taylor, ed., Chicago: Chicago University Press.

Taylor, J. (1999c), "The Robustness and efficiency of Monetary Policy Rules as Guidelines for Interest Rate Setting by the European Central Bank", Journal of Monetary Policy 43: $655-679$.

Weymark, D. (2004), "Economic structure, policy objectives, and optimal interest rate policy at low inflation rates", North American Journal of Economics and Finance 15: $25-51$. 
Table 1: Coefficients for Models 1 and 2 Based on Canadian Economiy

\begin{tabular}{c|l|c|c|c}
\hline Coefficient & \multicolumn{1}{|c|}{ Description } & Model 1 & Model 2 & Weymark \\
\hline$\alpha_{1}$ & First Lag Inflation on Inflation & 0.50 & 0.20 & 0.4964 \\
$\alpha_{1}{ }$ & Second Lag Inflation on Inflation & 0.00 & 0.30 & - \\
$\alpha_{2}$ & First Lag Output on Inflation & 0.15 & 0.15 & 0.1324 \\
$\beta_{1}$ & First Lag Output on Output & 0.90 & 0.90 & 0.9386 \\
$\beta_{2}$ & First Lag Instrument on Output & 0.75 & 0.75 & 0.7311 \\
\hline
\end{tabular}


Table 2: Panel Regression Coefficient Estimates

\begin{tabular}{|c|c|c|c|c|c|c|}
\hline \multicolumn{7}{|c|}{ Pooled Regression Results } \\
\hline & \multicolumn{2}{|c|}{ Fixed Effects } & \multicolumn{2}{|c|}{ Arellano and Bond } & \multicolumn{2}{|c|}{ Predicted } \\
\hline & Model 1 & Model 2 & Model 1 & Model 2 & Model 1 & Model 2 \\
\hline \multirow[t]{2}{*}{ Lagged Instrument } & $0.41^{*}$ & $0.51^{*}$ & $0.45^{\star}$ & $0.60^{*}$ & 0.00 & 0.00 \\
\hline & $(0.05)$ & (0.05) & $(0.05)$ & $(0.05)$ & & \\
\hline \multirow[t]{2}{*}{ Inflation } & $1.10^{*}$ & $1.00 *$ & $1.11^{*}$ & $1.09^{*}$ & 3.22 & 5.00 \\
\hline & $(0.06)$ & $(0.07)$ & $(0.06)$ & $(0.06)$ & & \\
\hline \multirow[t]{2}{*}{ Lagged Inflation } & $-0.20^{*}$ & $-0.53^{*}$ & -0.15 & $-0.41^{*}$ & 0.00 & 0.53 \\
\hline & $(0.06)$ & $(0.07)$ & $(0.07)$ & $(0.07)$ & & \\
\hline \multirow[t]{2}{*}{ Output } & $0.24 *$ & $0.15^{*}$ & $0.35^{\star}$ & $0.37^{\star}$ & 1.87 & 1.60 \\
\hline & $(0.06)$ & $(0.06)$ & $(0.06)$ & $(0.06)$ & & \\
\hline \multirow[t]{2}{*}{ Lagged Output } & -0.07 & $0.16^{*}$ & $-0.12^{*}$ & 0.04 & 0.00 & 0.00 \\
\hline & $(0.06)$ & $(0.06)$ & $(0.06)$ & 0.06 & & \\
\hline R-sq & 0.41 & 0.49 & & & & \\
\hline
\end{tabular}

Notes: Model 1: 56 subjects, 49 observations per subject Model 2: 58 subjects, 49 observations per subject

* indicates significance at the $5 \%$ level 
Figure 1: Model 1 Simulation Using The Optimal Rule

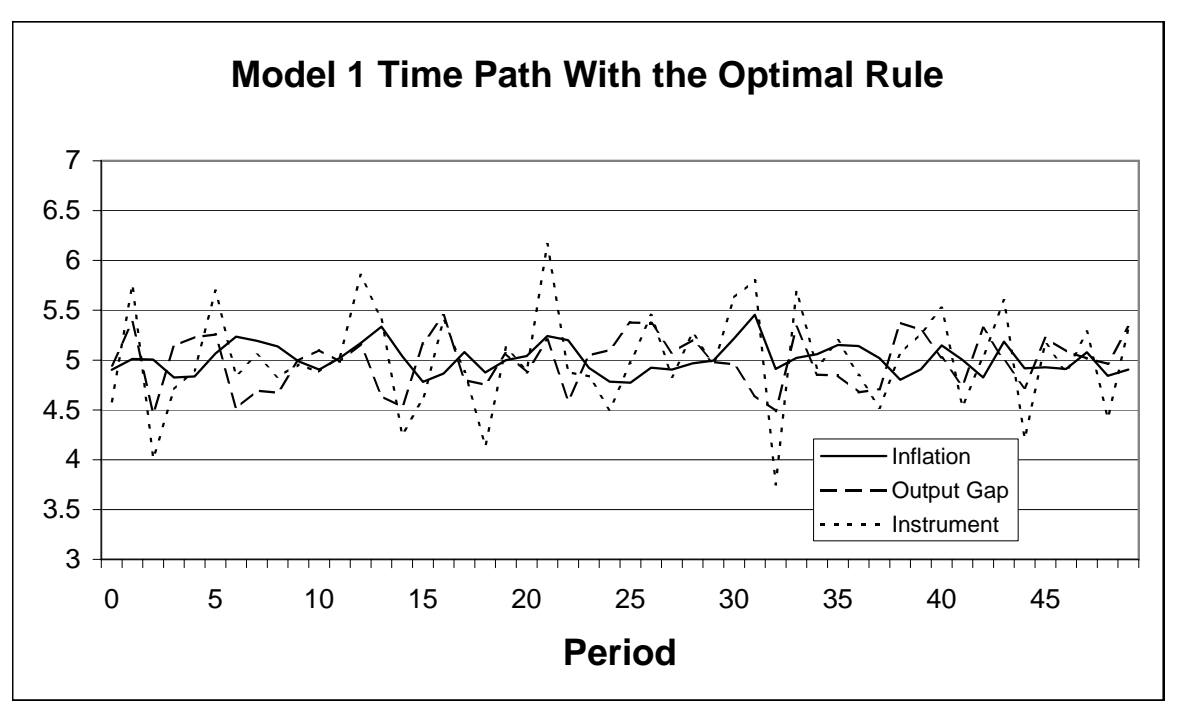

Figure 2: Model 2 Simulation Using The Optimal Rule

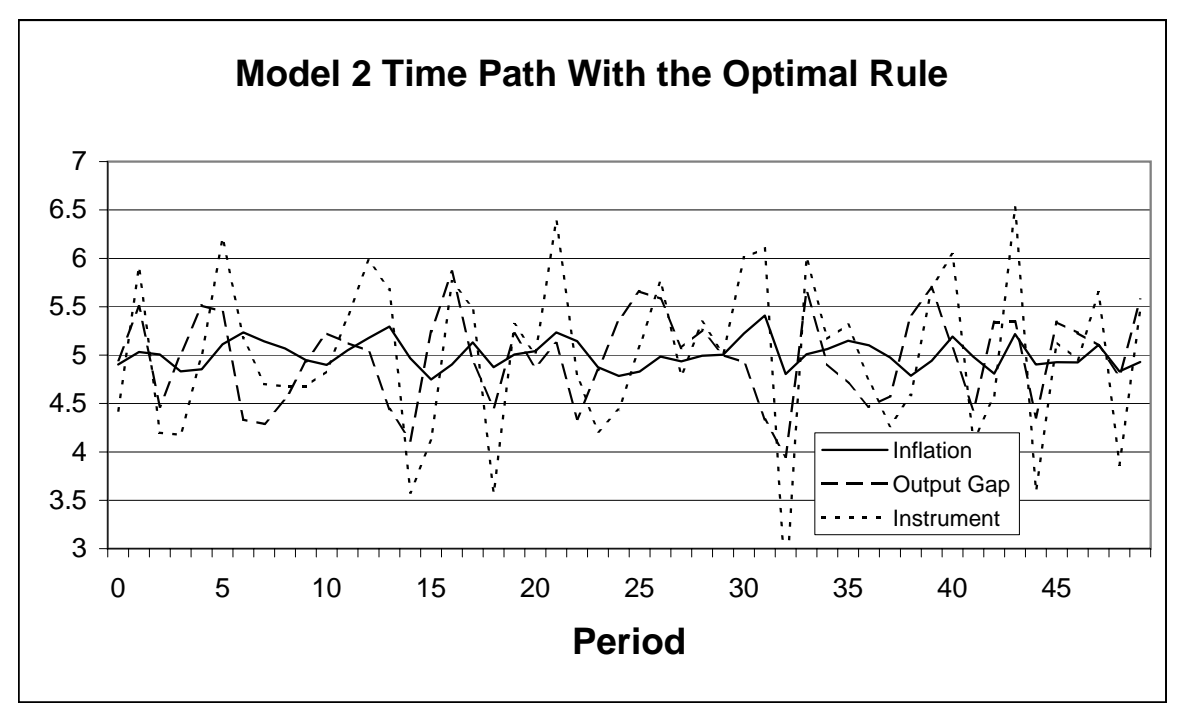


Figure 3: A Very Good Central Banker

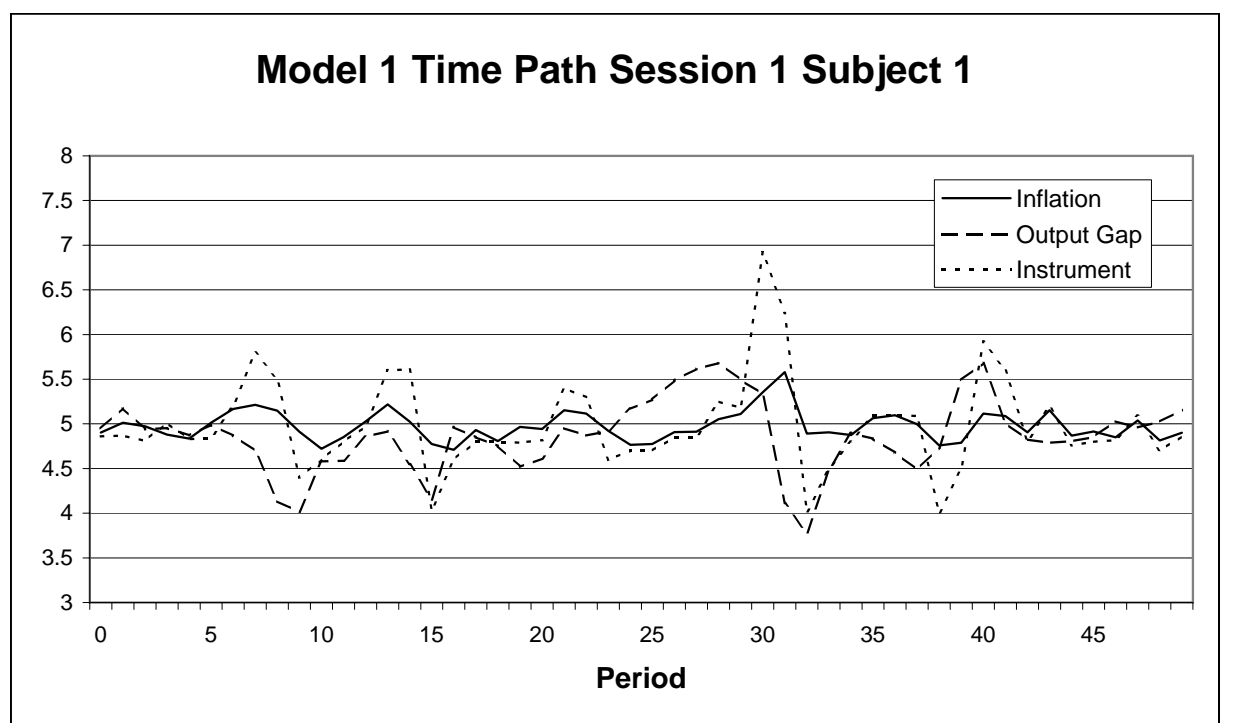

Figure 4: Increasing Variance Over Time

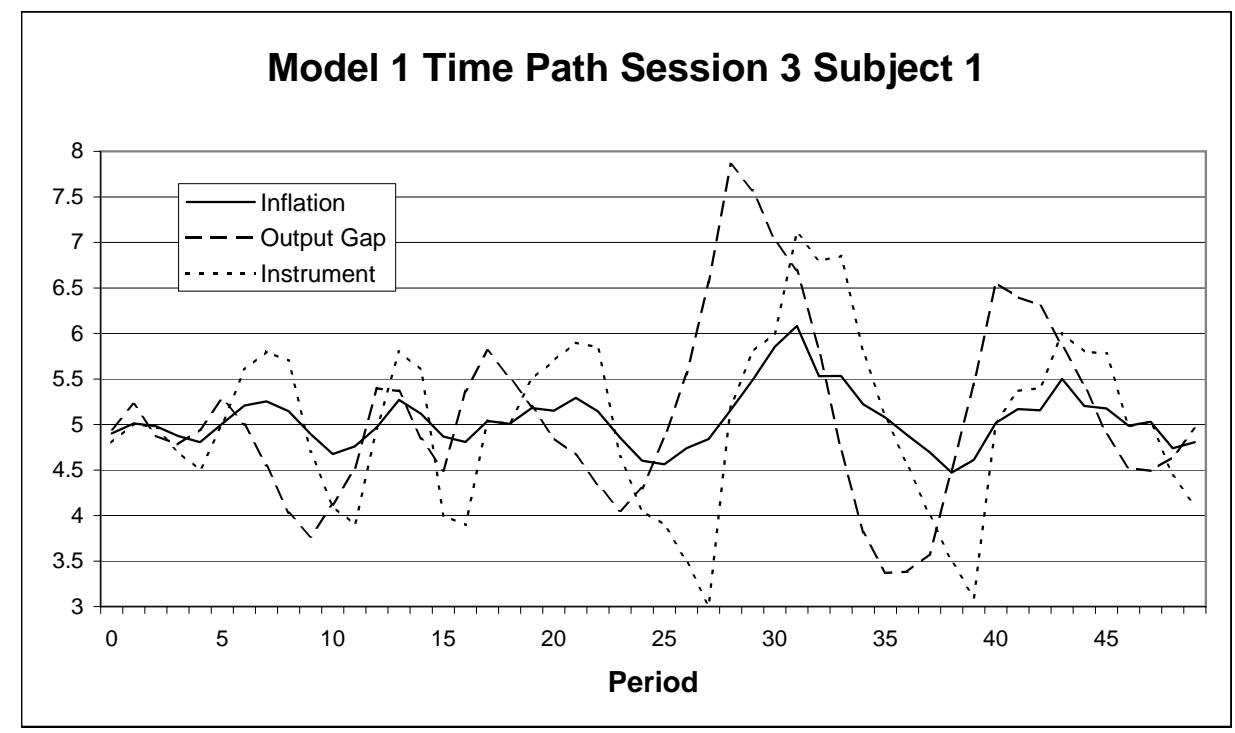


Figure 5:Losing Control

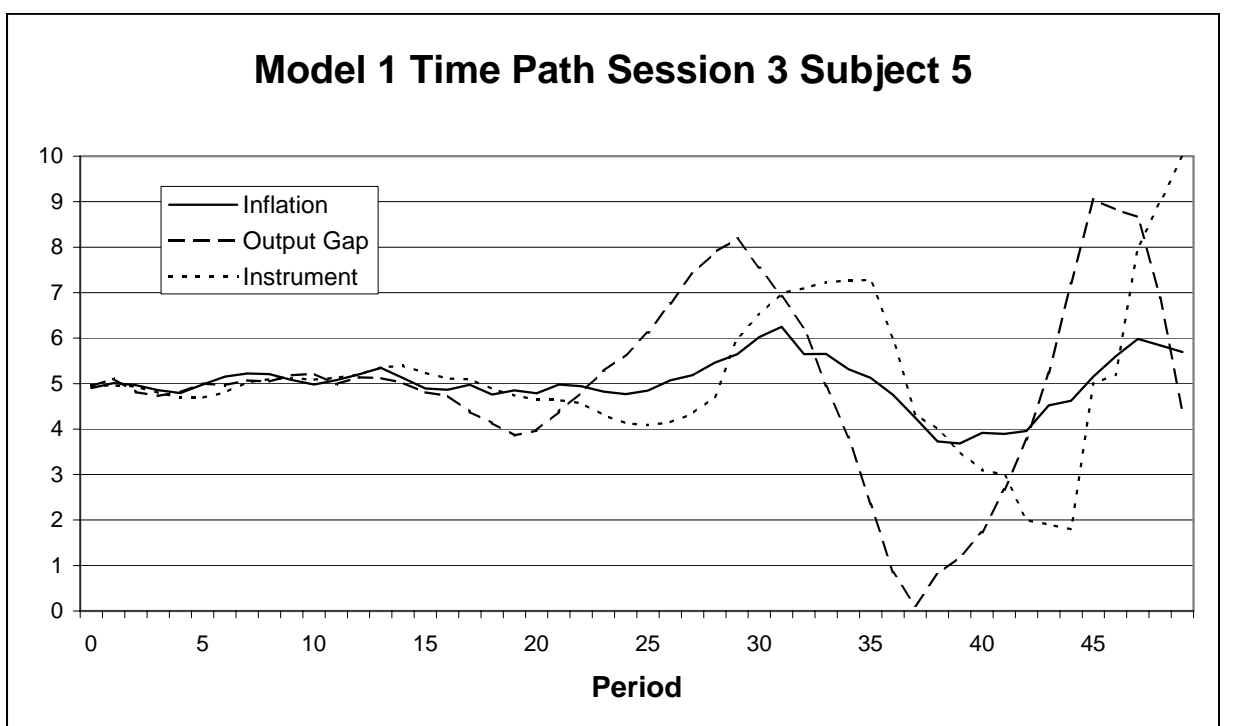

Figure 6:A Lost Cause

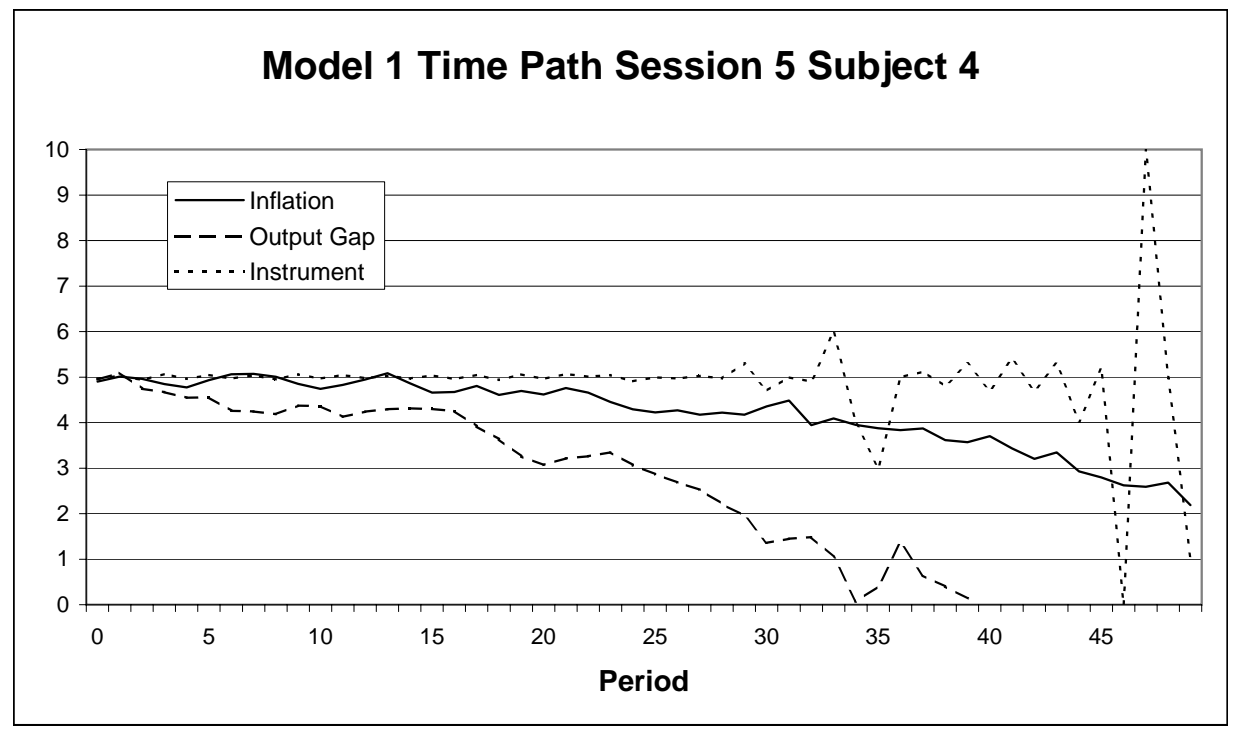


Figure 7: Another Very Good Central Banker

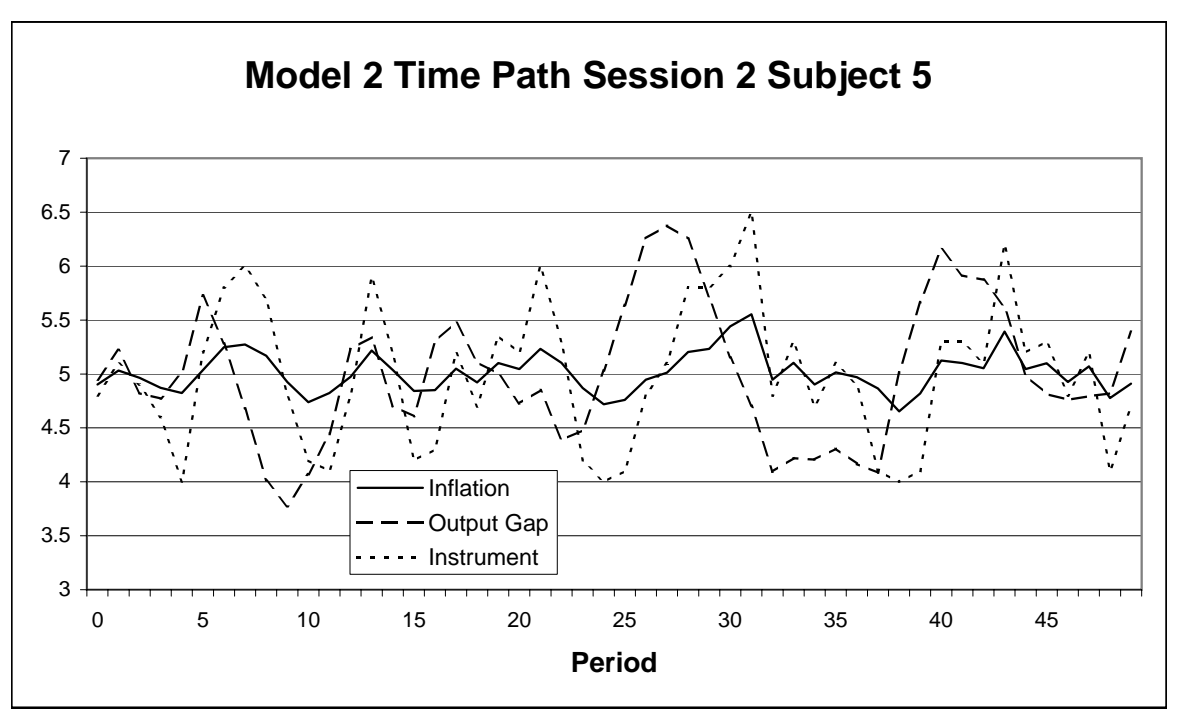

Figure 8: A Recovery

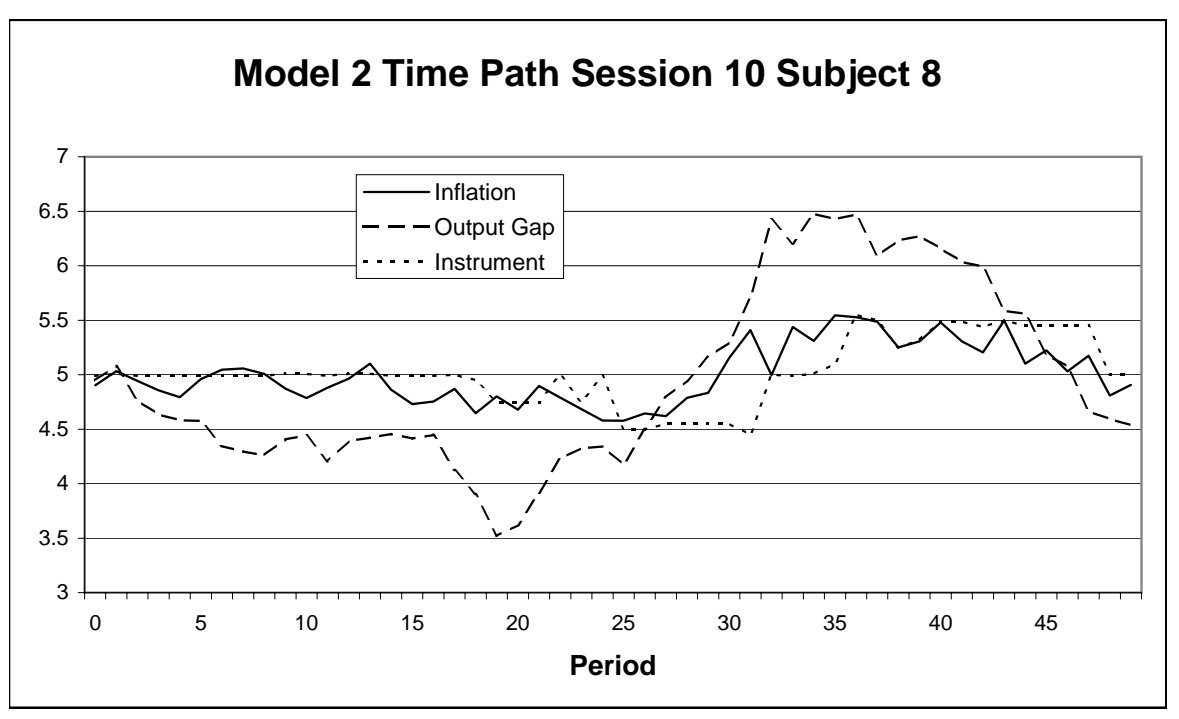


Figure 9: A Simple And Effective Rule

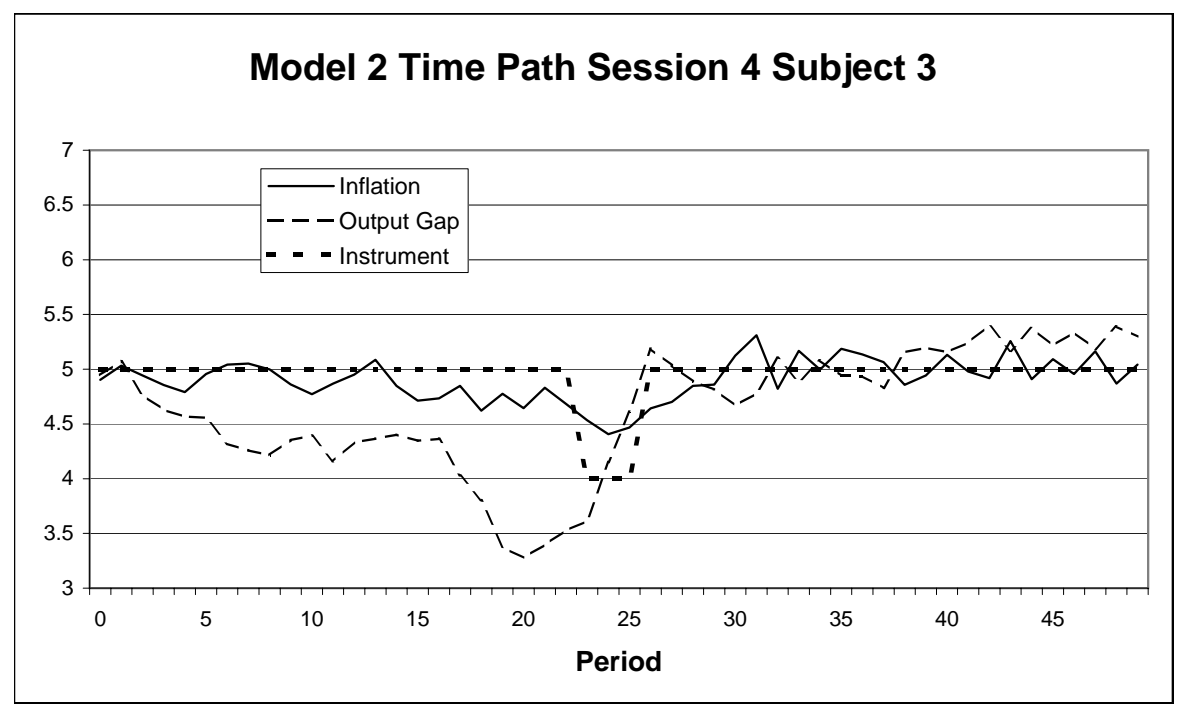

Figure 10: Another Lost Cause

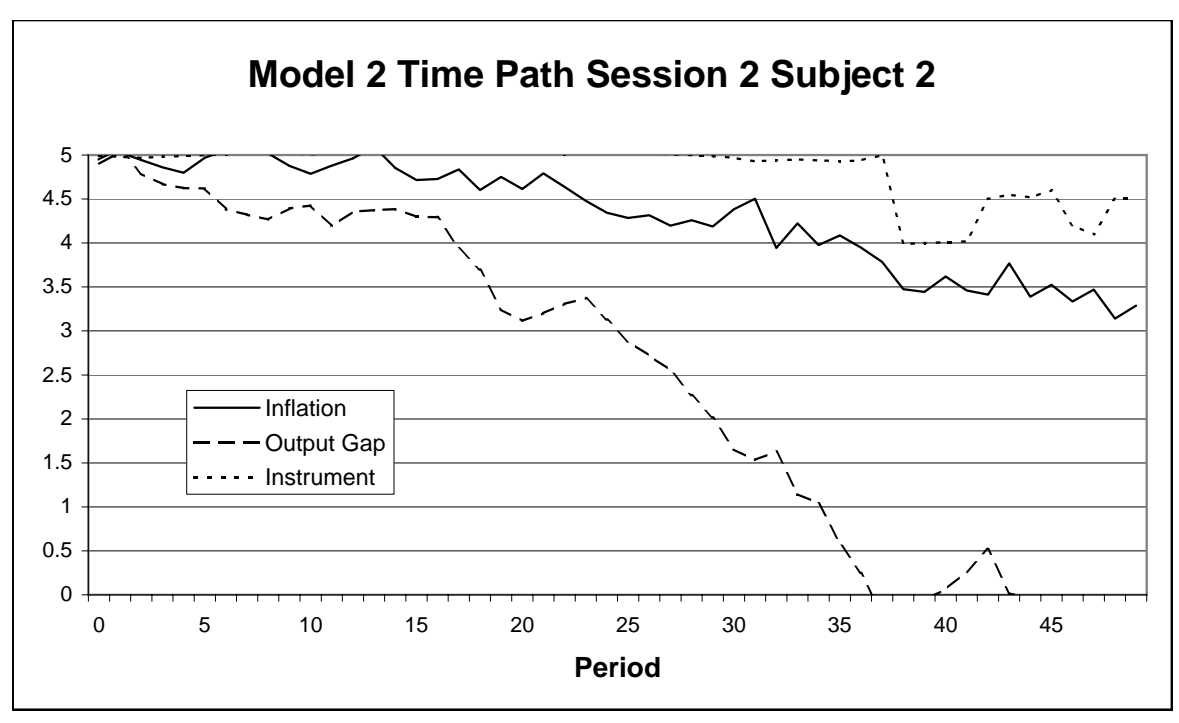


Figure 11: Distribution of OLS R-squared
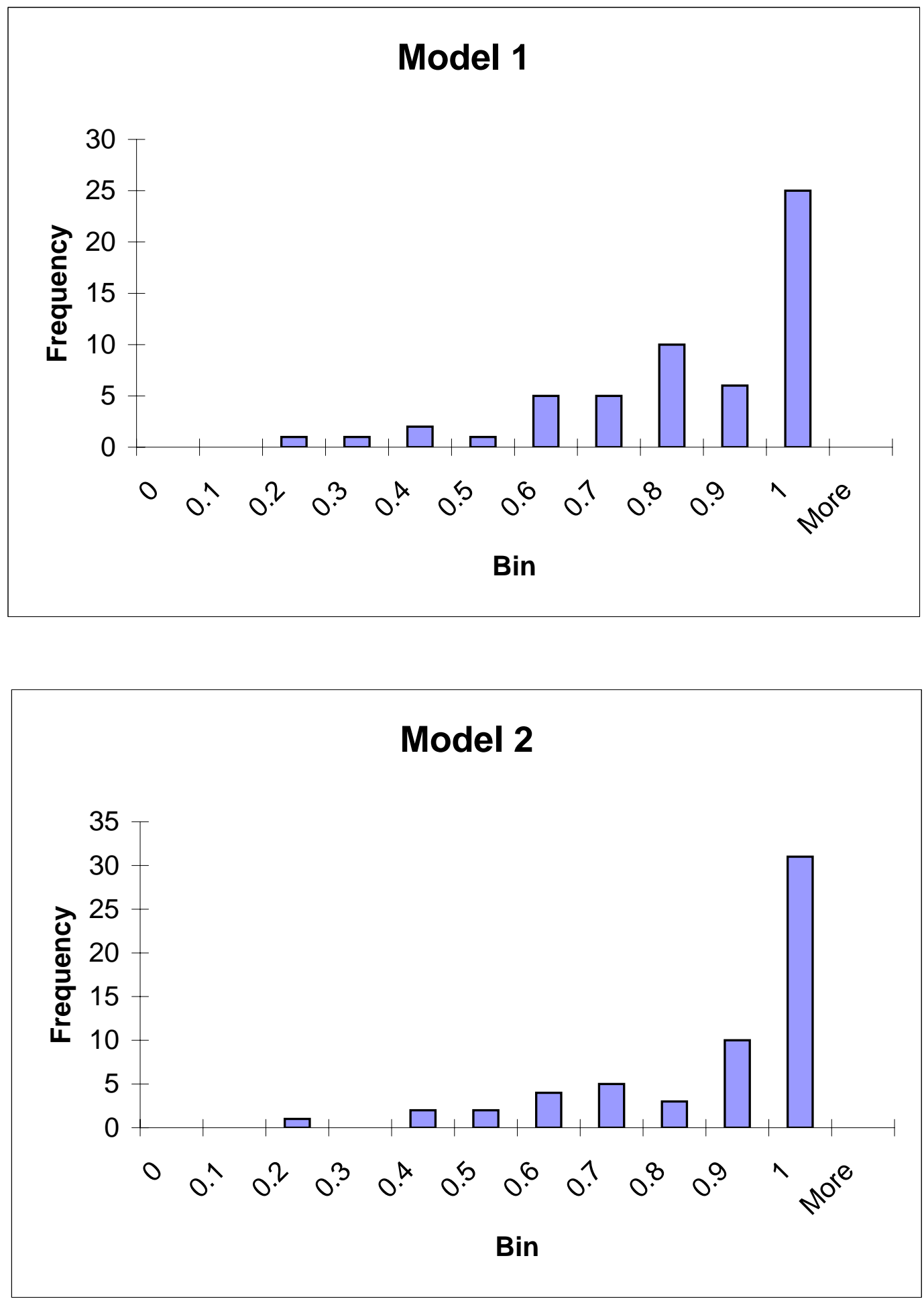
Figure 12: Distribution of OLS Estimates of Lagged Instrument Coefficient
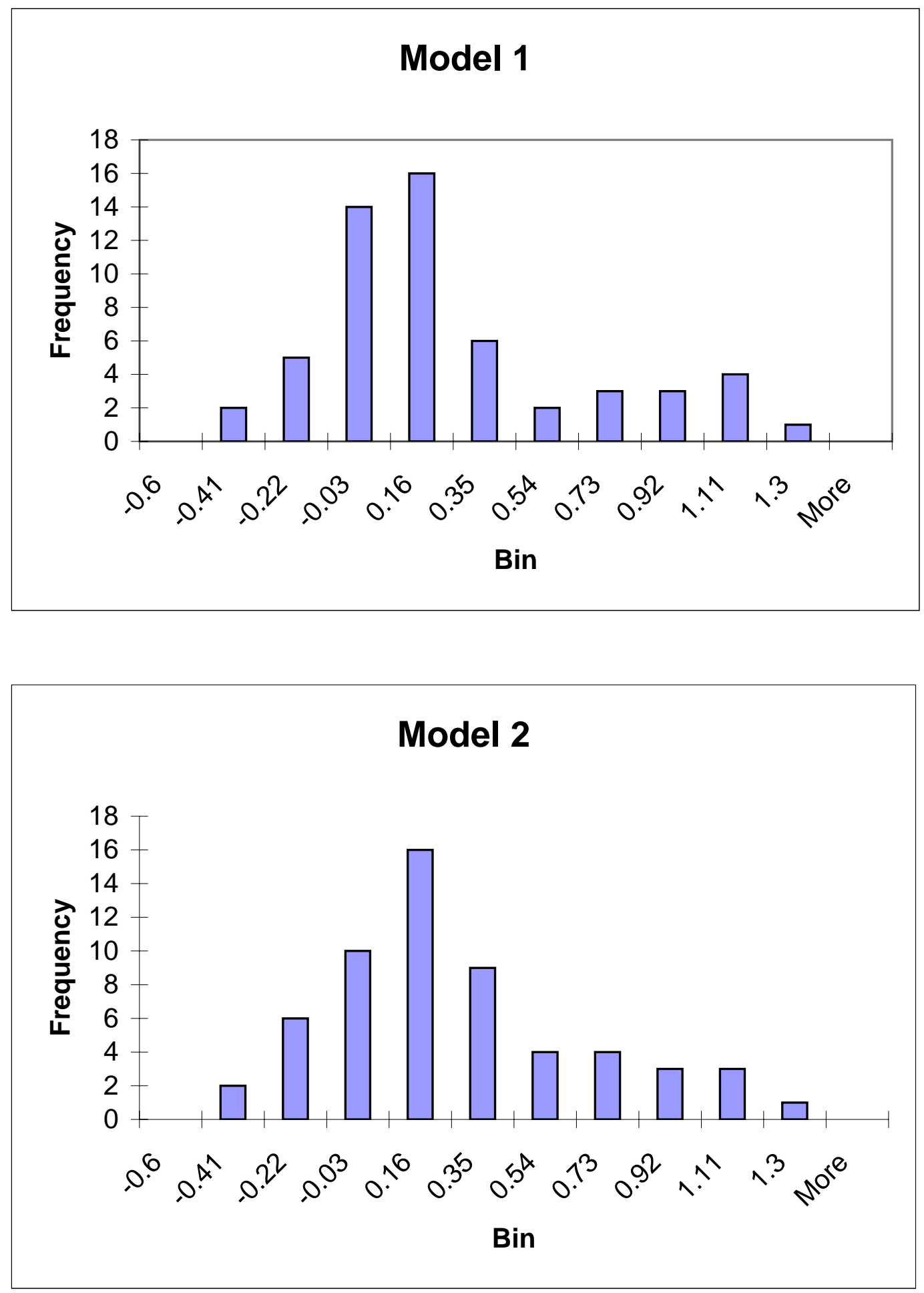
Figure 13: Distribution of OLS Estimates of Inflation Coefficient
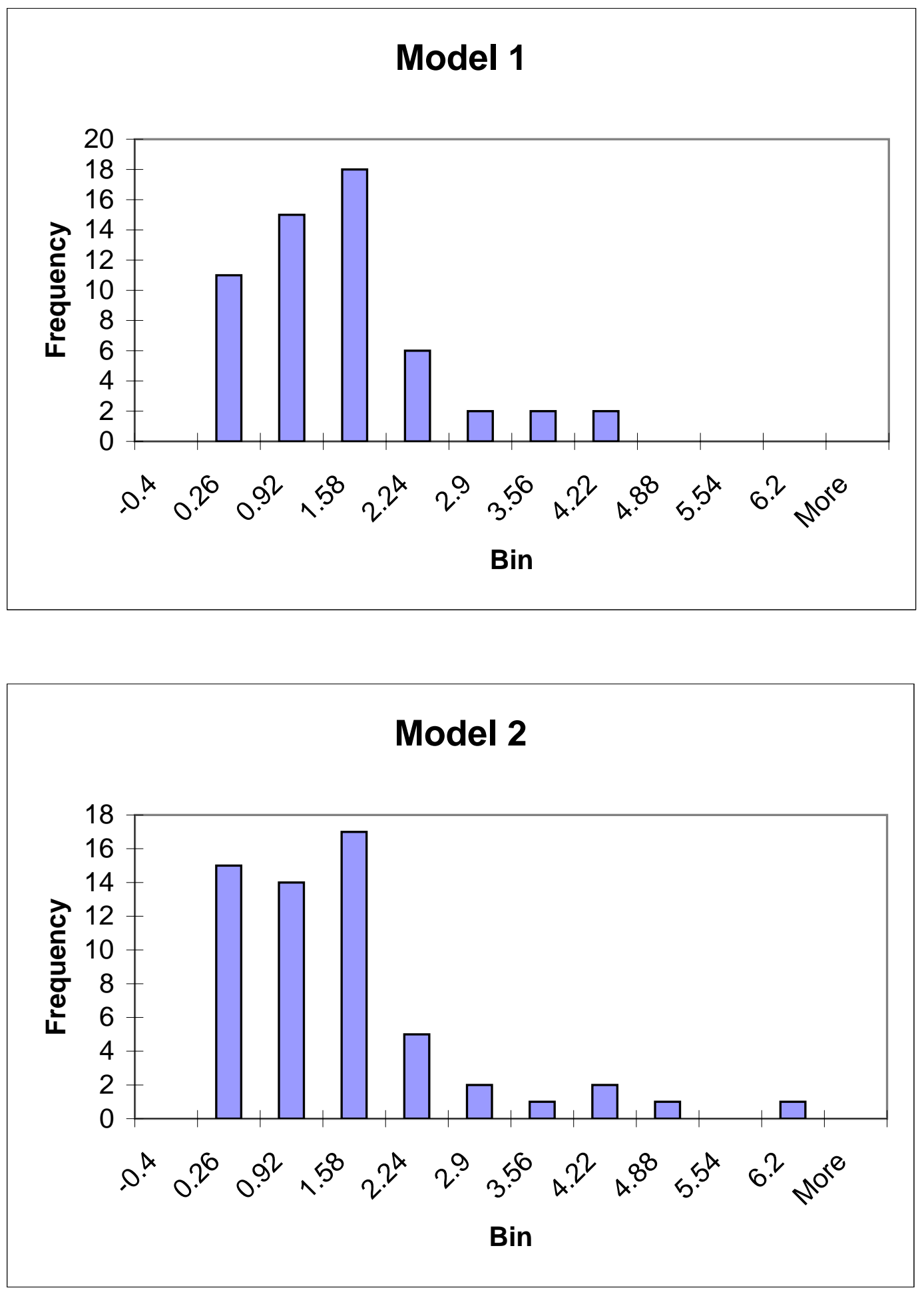
Figure 14: Distribution of OLS Estimates of Lagged Inflation Coefficient
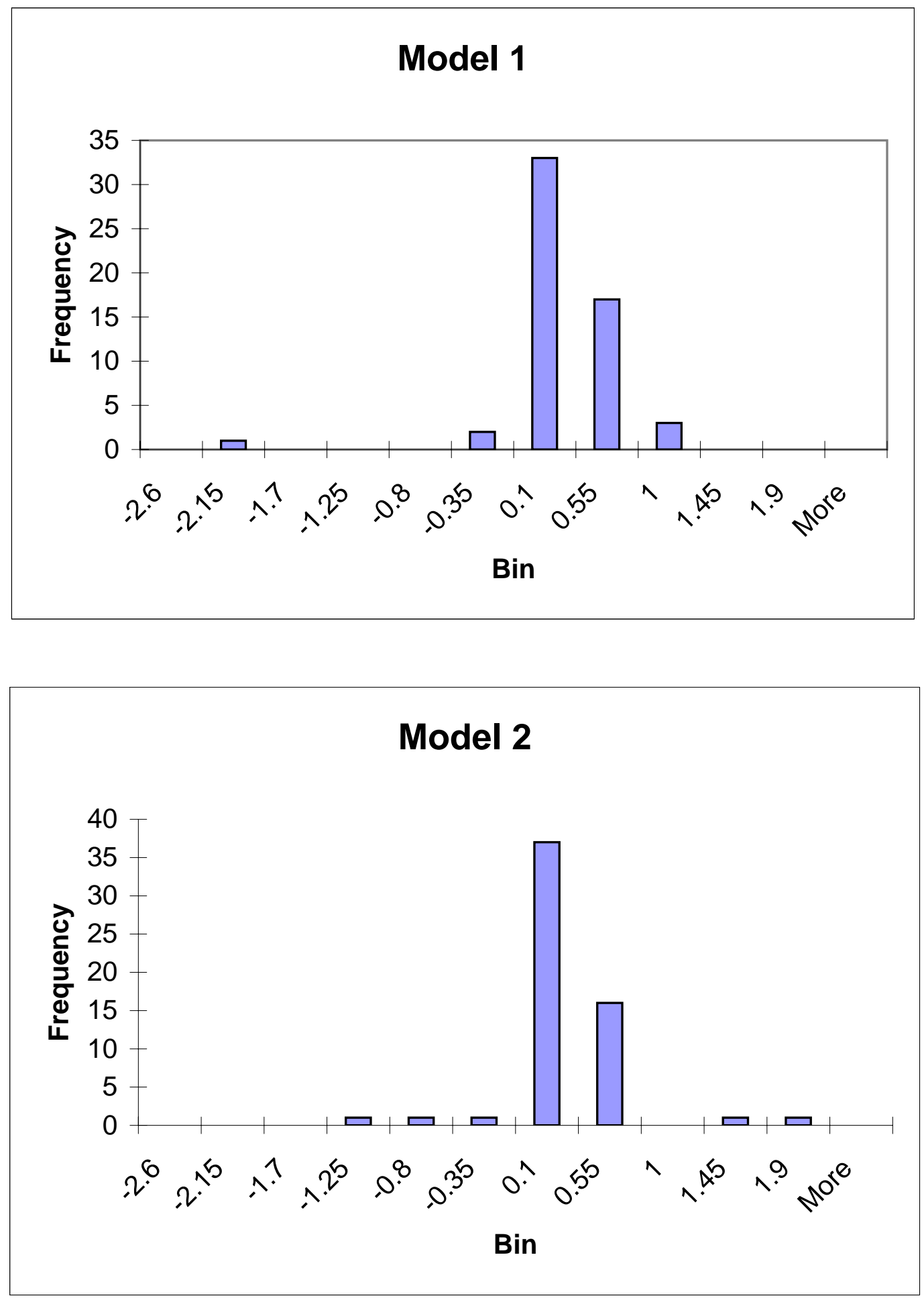
Figure 15: Distribution of OLS Estimates of Output Coefficient
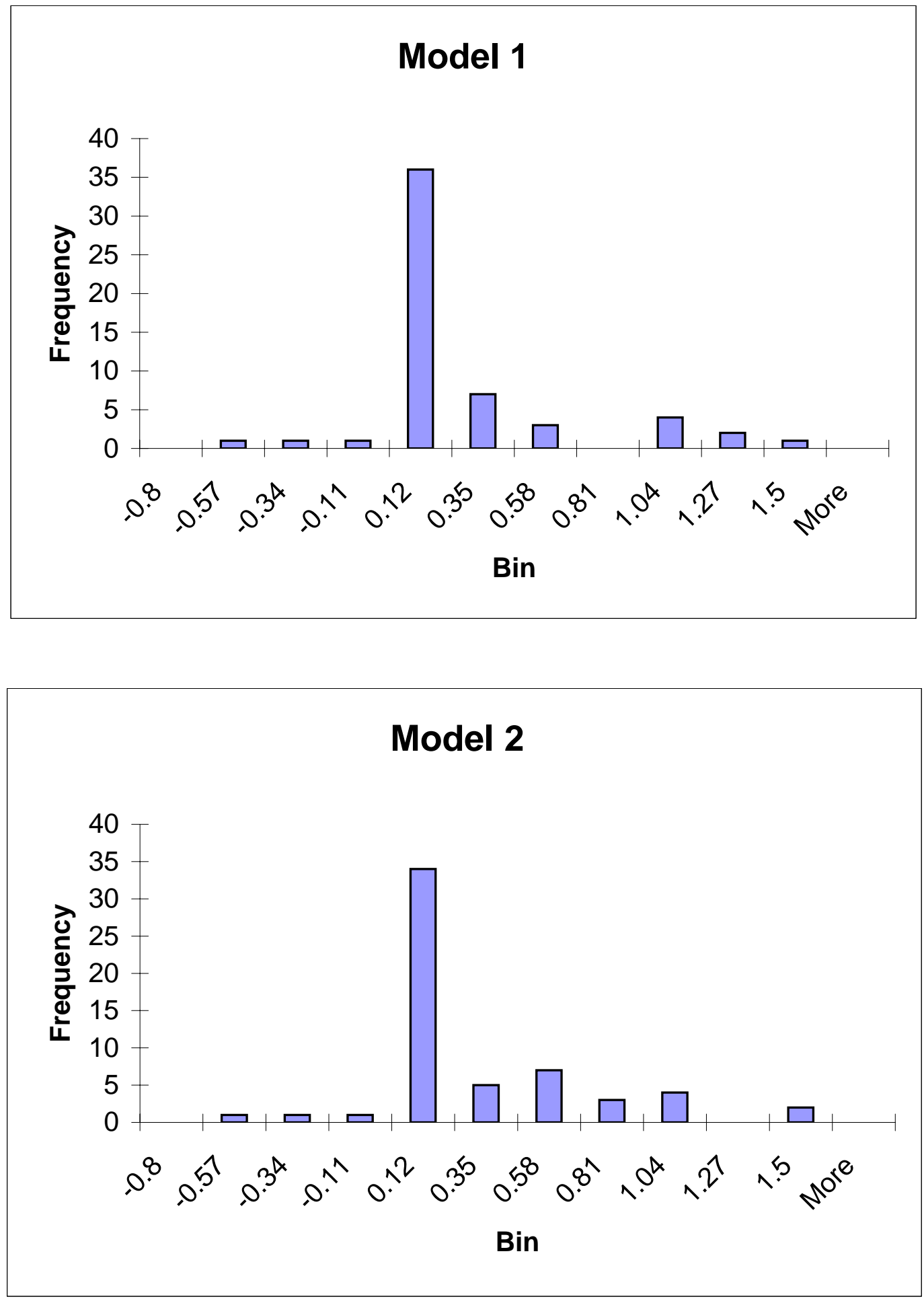
Figure 16: Distribution of OLS Estimates of Lagged Output Coefficient
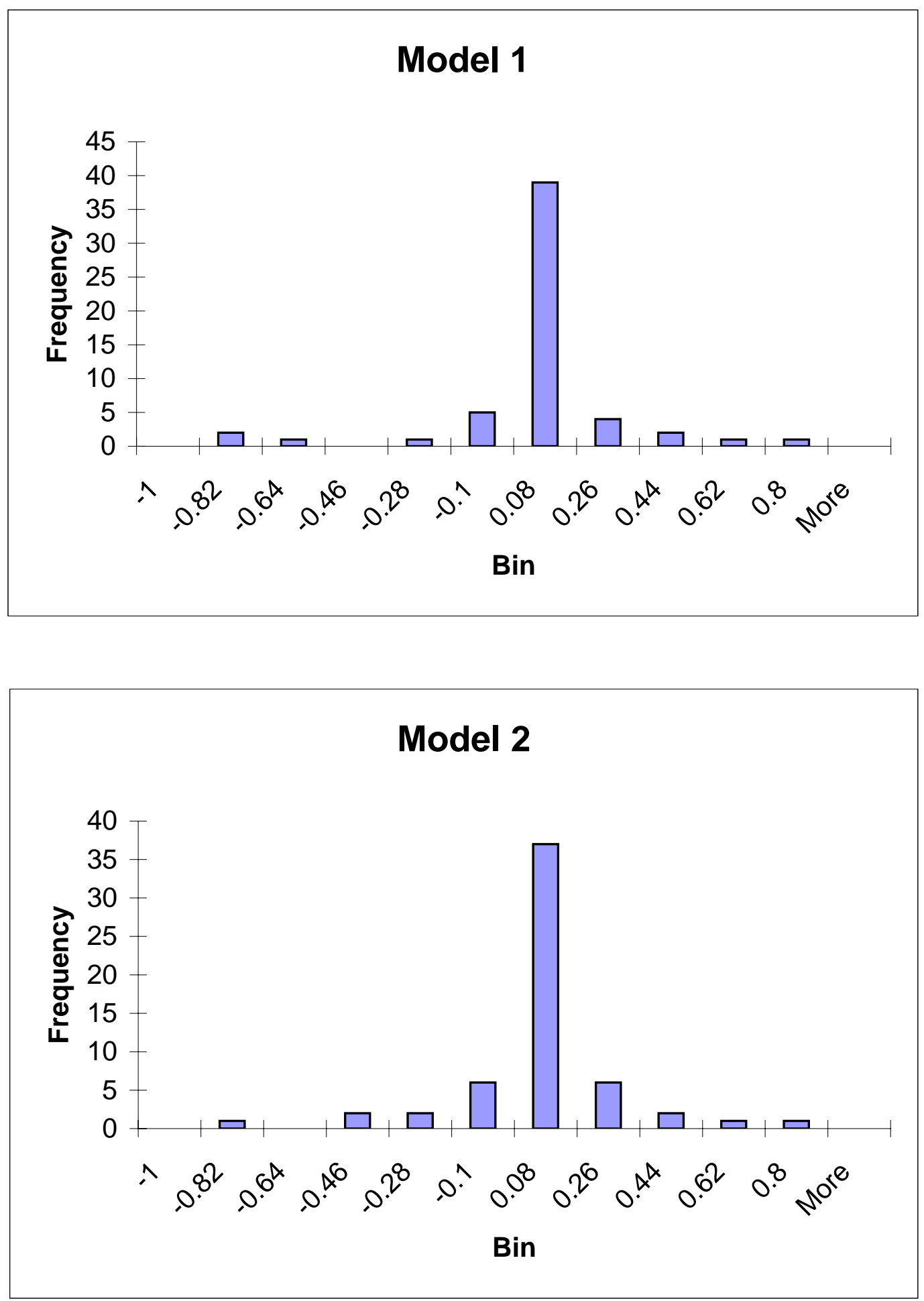
Figure 17: Expected Payoffs for Model 1
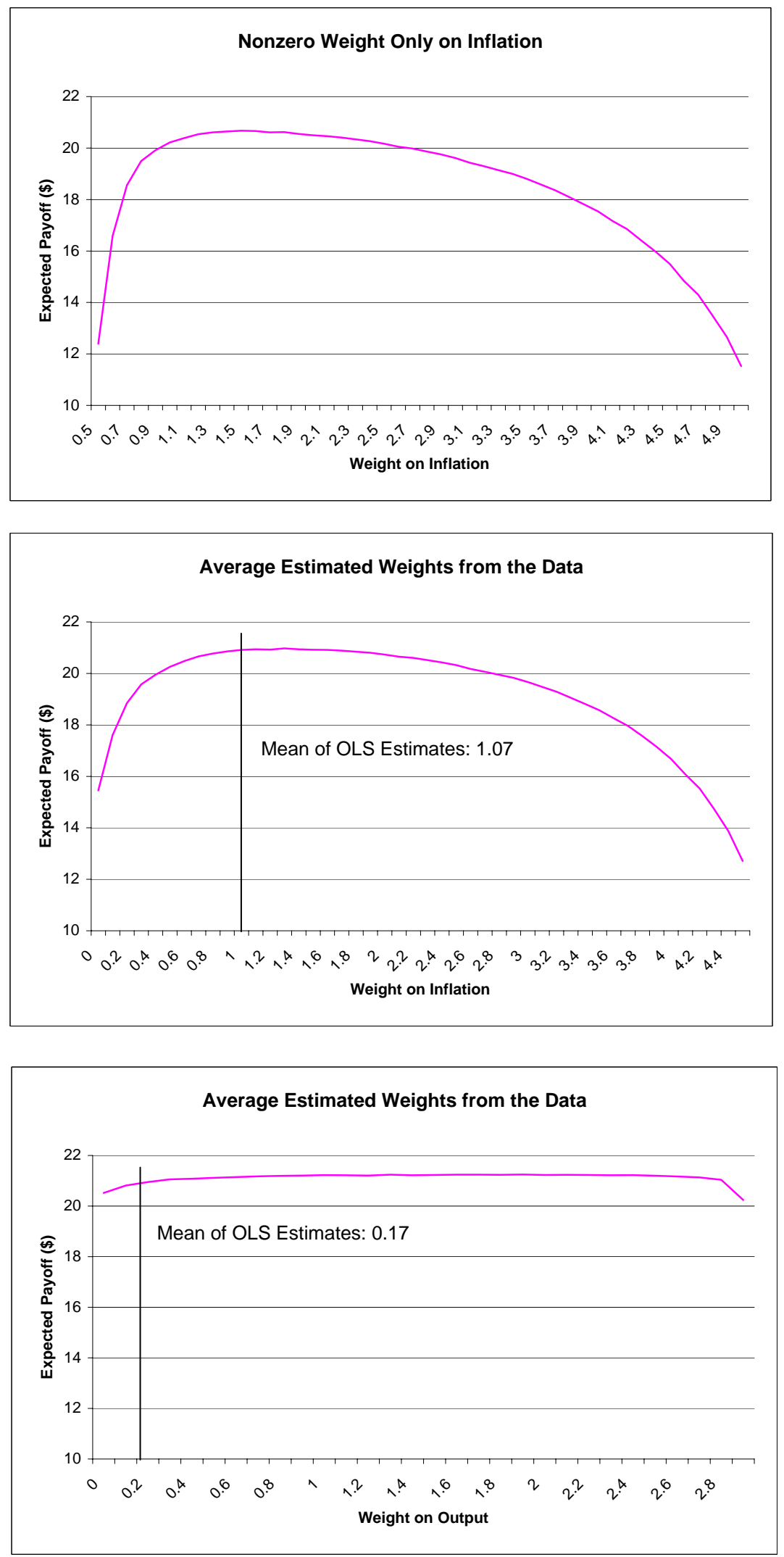
Figure 18: Expected Payoffs for Model 2
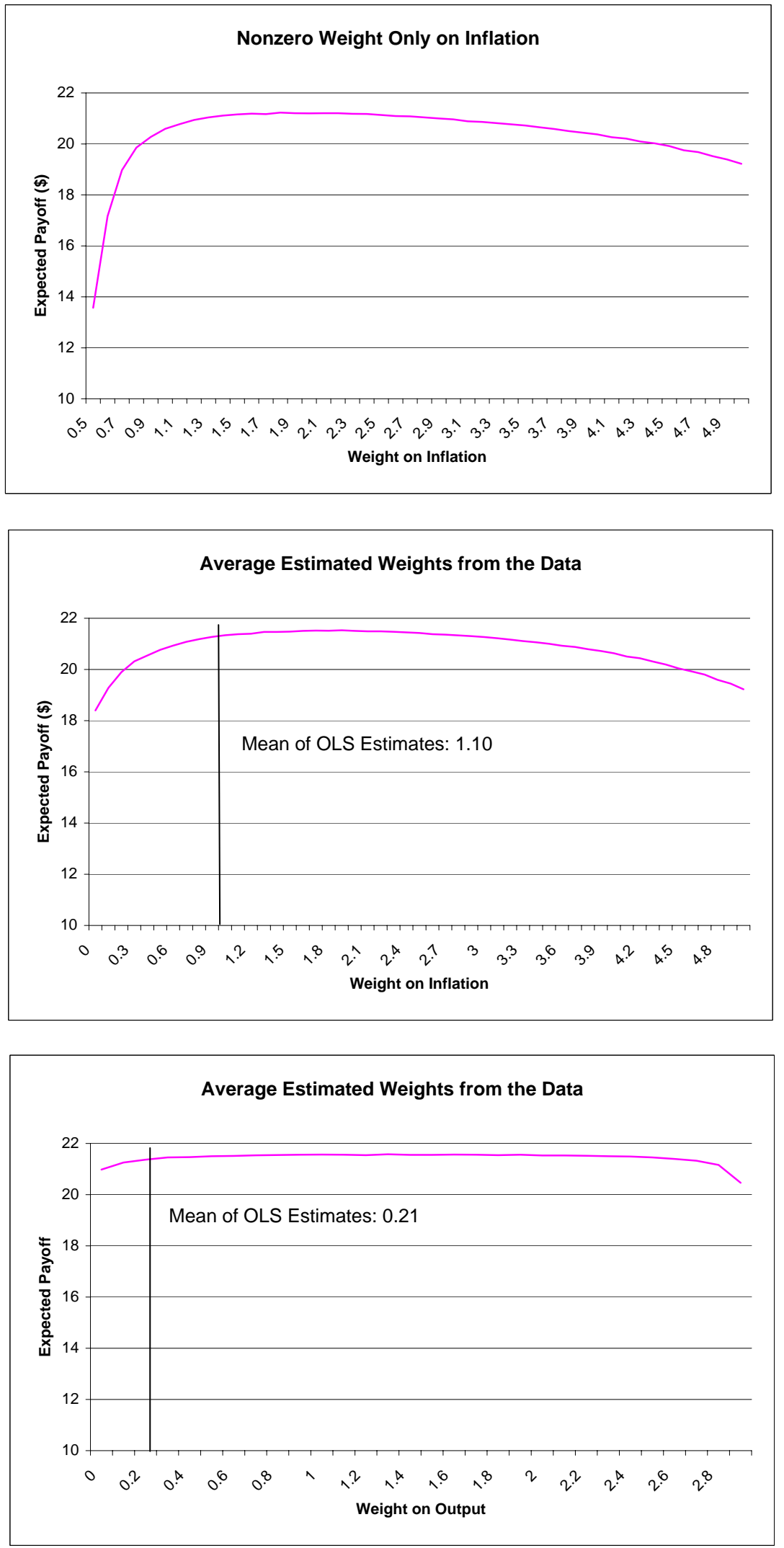